\title{
On the Need for Research-Tested Smartphone Applica- tions for Reducing Exposures to Known or Suspected Breast Carcinogens in Work and Home Environments
}

\author{
Steven S. Coughlin ${ }^{1 *}$, Molly Jacobs ${ }^{2}$, Herpreet Thind ${ }^{1}$, Nicole Champagne ${ }^{1}$, Benyuan Liu ${ }^{3}$, Margo Simon \\ Golden $^{4}$, Cheryl Osimo ${ }^{4}$, Natalicia Tracy ${ }^{5}$, Rachel I. Massey ${ }^{6}$
}

${ }^{1}$ Department of Community Health and Sustainability, Division of Public Health, University of Massachusetts, Lowell, MA

${ }^{2}$ Lowell Center for Sustainable Production, Lowell, MA

${ }^{3}$ Department of Computer Science, University of Massachusetts, Lowell, MA

${ }^{4}$ Massachusetts Breast Cancer Coalition, Boston, MA

${ }^{5}$ Brazilian Worker Center, Allston, MA

${ }^{6}$ Toxics Use Reduction Institute, Lowell, MA

*Corresponding Author: Dr. Steven Coughlin, PhD, Department of Community Health and Sustainability, Division of Public Health, University of Massachusetts, One University Avenue, Kitson Hall 313A, Lowell, MA 01854. Tel: (404) 983-2524; E-mail: steven_coughlin@uml.edu

Citation: Coughlin, S.S., et al. On the Need for Research-Tested Smartphone Applications for Reducing Exposures to Known or Suspected Breast Carcinogens in Work and Home Environments. (2015) J Environ Health Sci 1(4): 1-2.

\section{Editorial}

Rapid technological developments have led to the development of smartphones that combine the voice and text messaging functions of cellular phones with computing technology that can support Internet access and third-party applications ${ }^{[1]}$. Major smartphone platforms provide third-party developers with application programming interfaces that can be used to build special purpose applications referred to as native apps ${ }^{[1]}$. To an increasing extent, smartphones are gaining widespread use in health promotion research and practice. For example, smartphone apps have been developed and shown to be effective for promoting healthy diet and nutrition, weight control, physical activity, and other behaviors associated with reduced risk of breast cancer and a variety of other chronic diseases ${ }^{[2,3]}$. Smartphone apps for promoting healthy behaviors should be based on health behavior theories and frameworks and include evidence-based features such as positive reinforcement and self-monitoring.

Several web-based databases --for example, the Chemical Hazard and Alternatives Toolbox (ChemHat), the Pharos Project, Haz-Map, the U.S. Library of Medicine's Genetic Toxicology Database (GENE-TOX), Environmental Working Group resources, and the California State Office of Environmental Health Hazard Assessment's Proposition 65 list of chemicals ${ }^{[4-9]}$ have been developed for providing information about toxic chemicals, including known or suspected breast cancer carcinogens. Not all of these databases, however, are intended for use by lay persons who are not well-versed in toxicology, occupational health and safety, or environmental epidemiology, and some key resources require a paid subscription. In a synthesis of scientific data from national and international sources, Silent Spring Institute researchers identified 216 chemicals that caused increased mammary tumors in an animal study ${ }^{[10]}$. An estimated 100 of these chemicals are likely common sources of exposure in everyday life. For example, people are exposed to carcinogenic polycyclic aromatic hydrocarbons (PAHs) in grilled and smoked food, tobacco smoke, and air pollution from auto exhaust. Ethylene oxide is used in hospitals and other medical facilities to sterilize instruments ${ }^{[10]}$. Mammary carcinogens are also found in certain furniture finishes, dyes, and solvents. Although conclusive evidence from epidemiologic studies is lacking, it is plausible that exposures to chemicals with estrogenic or other properties relevant to sex steroid activity (e.g., bisphenol A, polybrominated diphenyl ethers, and certain dioxins or dioxin-like compounds) could influence breast cancer risk if the exposures occur at critical life stages or in combination with exposure to similar chemicals ${ }^{[1]}$. Several studies have found an association between shift work and disruption of the circadian rhythm and risk of breast cancer ${ }^{[12]}$. 
To date, smartphone apps for reducing exposures to known or suspected breast carcinogens in work or home environments have not been tested for acceptability, feasibility, or effectiveness in randomized controlled trials. The extent to which women with lower levels of health literacy or numeracy find smartphone apps useful or practical, and whether apps are effective in helping culturally diverse groups of women to reduce their risk of breast cancer, is unknown. Our collaborative group is working towards the development and testing of culturally tailored educational materials for breast cancer prevention among women with different cultural backgrounds. We plan to use a community-engaged approach to prepare and refine educational materials that can be placed on a computer server and accessed via smartphone app. The planning group includes representatives of the University of Massachusetts at Lowell Department of Community Health Science and Sustainability, and Computer Science; the Massachusetts Breast Cancer Coalition; the Lowell Center for Sustainable Production, and the Toxics Use Reduction Institute. Several resources will be used to summarize information about known or suspected carcinogens including existing databases and published systematic reviews. The women will also be informed that shift-work that involves disruption of the circadian rhythm is a probable breast carcinogen, and how to reduce that risk. Information about other modifiable risk factors in the workplace or home settings will also be included. Our long-term goal is to develop and test the effectiveness of a smartphone app, with graphic designs, visual images, and narrative text (in English and other languages), in promoting healthy lifestyles and assisting women with varying levels of health literacy and numeracy to minimize their exposure to known or suspected carcinogens in occupational and home settings.

\section{References}

1. Bender, J.L., Yue, R.Y., To, M.J., et al. A lot of action, but not in the right direction: systematic review and content analysis of smartphone applications for the prevention, detection, and management of cancer. (2013) J Med Internet Res 15(12): e287.

2. Coughlin, S.S., Whitehead, M., Sheats, J.Q., et al. Smartphone applications for promoting healthy diet and nutrition: a literature review. (2015) J Diet Nutr [in press].

3. Middelweerd, A., Mollee, J.S., van der Wal, C.N., et al. Apps to promote physical activity among adults: a review and content analysis. (2014) Int J Behav Nutr Phys Act 11: 97.

4. Chemical Hazard and Alternatives Toolbox.

5. The Pharos Project

6. Haz-Map

7. U.S. Library of Medicine Genetic Toxicology Database

8. The Environmental Working Group

9. Office of Environmental Health Hazard Assessment(OEHHA).

10. Silent Spring Institute

11. Ekenga, C.C., Parks, C.G., D’Aloisio, A.A., et al. Breast cancer risk after occupational solvent exposure: the influence of timing and setting. (2014) Cancer Res 74(11): 3076-3083.

12. He, C., Anand, S.T., Ebell, M.H., et al. Circadian disrupting exposures and breast cancer risk: a meta-analysis. (2015) Int Arch Occup Environ Health 88(5): 533-547.
Ommega Online Publishers

Journal Title: Journal of Environment and Health Science (JEHS)

Journal Short Name: J Environ Health Sci
Journal ISSN: 2378-6841

E-mail: environmentalscience@ommegaonline.org

Website: www.ommegaonline.org 